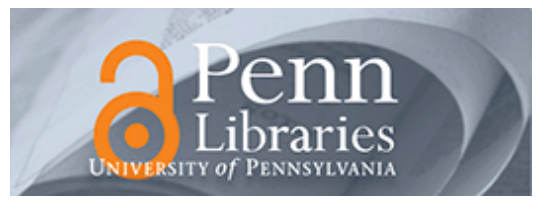

University of Pennsylvania

ScholarlyCommons

Management Papers

Wharton Faculty Research

2011

\title{
Is There an eBay for Ideas? Insights From Online Knowledge \\ Marketplaces
}

Gary Dushnitsky

University of Pennsylvania

Thomas Kleuter

University of Pennsylvania

Follow this and additional works at: https://repository.upenn.edu/mgmt_papers

Part of the Business Administration, Management, and Operations Commons, E-Commerce Commons, Management Information Systems Commons, and the Marketing Commons

\section{Recommended Citation}

Dushnitsky, G., \& Kleuter, T. (2011). Is There an eBay for Ideas? Insights From Online Knowledge Marketplaces. European Management Review, 8 (1), 17-32. http://dx.doi.org/10.1111/

j.1740-4762.2010.01002.x

This paper is posted at ScholarlyCommons. https://repository.upenn.edu/mgmt_papers/15

For more information, please contact repository@pobox.upenn.edu. 


\title{
Is There an eBay for Ideas? Insights From Online Knowledge Marketplaces
}

\begin{abstract}
The market for knowledge has grown dramatically over the past decades. Extant work underscores the factors shaping market efficacy: (a) the cost of searching for innovative knowledge; (b) asymmetricinformation between inventors and investors; and (c) the inherent difficulty in maintaining ownership over knowledge. Recently, market transactions have been taking place online, matching disperse owners (entrepreneurs or inventors), and seekers (investors or licensees), of knowledge. This phenomenon constitutes a sharp departure from past practices where transactions tend to materialize around one's social circle (e.g., venture capitalists' social ties). We investigate the drivers of market efficacy in a setting where social ties are not available ex-ante, and identify alternative market mechanisms that emerge in such settings. Using novel hand-collected data for 30 online knowledge marketplaces, we find overwhelming evidence of adverse-selection-mitigating mechanisms (e.g., screening through upfront fees and disclosure requirements). We discuss theoretical explanations that are consistent with the observed mechanisms.
\end{abstract}

\section{Keywords}

market for ideas, entrepreneurship, innovation, open innovation, venture capital

\section{Disciplines}

Business Administration, Management, and Operations | E-Commerce | Management Information Systems | Marketing 


\title{
IS THERE AN $e$ Bay FOR IDEAS? INSIGHTS FROM ONLINE KNOWLEDGE MARKETPLACES
}

\author{
Gary Dushnitsky \\ London Business School \\ Sainsbury Building, Suite S331 \\ Sussex Place, Regent's Park \\ London NW1 4SA \\ gdushnitsky@london.edu
}

\author{
Thomas Klueter
}

The Wharton School

University of Pennsylvania

Steinberg Hall - Dietrich Hall

Philadelphia, PA 19104

klueter@wharton.upenn.edu

Original Draft: January 19, 2009

This Draft: October 26, 2010

Forthcoming in:

European Management Review

\begin{abstract}
We would like to thank the editor, Alfonso Gambardella, and two anonymous referees for helpful suggestions. We also appreciate useful comments from participants at ACE Entrepreneurship conference, DIME conference, the 2009 Israel Strategy Conference, the 2009 Strategic Management Society, and the 2009 Academy of Management Conference. Dushnitsky acknowledges financial support from the Kauffman Foundation (Junior Faculty Fellowship, 2009) and Chris Ingram Strategy, Entrepreneurship and Leadership Fund (2010). (C) Dushnitsky \& Klueter, 2010.
\end{abstract}




\title{
Is There an $e$ Bay for Ideas? Insights from Online Knowledge Marketplaces
}

\begin{abstract}
The market for knowledge grew dramatically over the past decades. Extant work underscores the factors shaping market efficacy: (a) the cost of searching for innovative knowledge, (b) asymmetric-information between inventors and investors, and (c) the inherent difficulty in maintaining ownership over knowledge. Recently, market transactions have been taking place online, matching disperse owners (entrepreneurs or inventors) and seekers (investors or licensees) of knowledge. This phenomenon constitutes a sharp departure from past practices where transactions tend to materialize around one's social circle (e.g., venture capitalists' social ties). We investigate the drivers of market efficacy in a setting where social ties are not available ex-ante, and identify alternative market mechanisms that emerge in such settings. Using a novel hand-collected data for 30 online knowledge marketplaces, we find overwhelming evidence of adverse-selection-mitigating mechanisms (e.g., screening through upfront fees and disclosure requirements). We discuss theoretical explanations that are consistent with the observed mechanisms.
\end{abstract}




\section{Is There an $e$ Bay for Ideas? Insights from Online Knowledge Marketplaces}

The past decades witnessed a qualitative shift in the importance of knowledge assets, as well as the means of transacting for them. Markets for knowledge and technology grew dramatically, reaching about $\$ 300$ billion globally during the period 1990-1997 (Arora, Fosfuri,

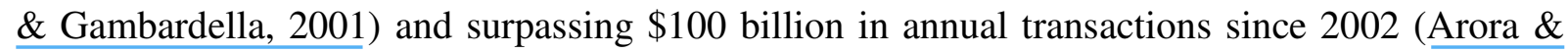
Gambardella, 2009; OECD, 2006; Robbins, 2009). Not only is there evidence that knowledge assets can be valuable (e.g., Gambardella, Harhoff and Verspagen, 2008), but also that the forces driving technology transactions stem from both shifts in supply and demand for such knowledge (Zahra, Keil and Maula, 2005). At the same time, the market for technology can expand with the growth of patents in new fields (e.g., Hall, Thoma and Torrisi, 2009). More recently, economic transactions have been increasingly taking place online. We argue that the shift towards online marketplaces creates many new opportunities, which are comparable to physical goods marketplaces (e.g., eBay). Accordingly, this paper explores if there could be an $e$ Bay for ideas?

Prior work suggests that the ability to achieve efficient trade in knowledge is a function of several factors including search costs, information asymmetries, and the threat of knowledge expropriation. The shift towards online marketplaces creates many new opportunities for more efficient trade because the cost of searching and executing a transaction has decreased. But it also gives rise to substantial problems. Online marketplaces are a particularly attractive setting for malfeasant individuals who pose as owners of valuable inventions, thus increasing the problem of adverse selection due to asymmetric information. And, those with valuable inventions may find that posting an idea online significantly increases the risk of expropriation. It follows that online marketplaces for ideas entail great benefits as well as challenges: they reduce search costs but raise adverse selection problems and risks of expropriation. 
The purpose of this paper is to understand the effect of these factors on online markets for knowledge. To that end, we study thirty of the most prominent websites that act as marketplaces where owners of knowledge (e.g. an inventor of a patent, or an entrepreneur with an innovative business idea) interact with knowledge seekers (e.g., potential licensees, or prospective investors). Consistent with extant theory, we find that a significant proportion (27 of 30) of the marketplaces adopt adverse selection mitigating mechanisms. Such screening mechanisms include the requirement to list a detailed description of the knowledge (i.e., disclosure of the business idea, discussion of the patent and its potential applications), or the enforcement of upfront participation fee (i.e., effectively linking owners' ultimate gains to the quality of their inventions). We further explore whether these mechanisms are affected by the threat of expropriation, as extant theory predicts. The evidence is inconclusive as to whether the adoption of disclosure requirement is sensitive to environmental (i.e., the strength of the intellectual property regime) or individual (i.e., knowledge owners' tacit knowledge) factors.

The paper makes several contributions. First, to the best of our knowledge this is the first study, with the exception of Palomeras (2007), to examine online knowledge marketplaces through the lens of the market for technology literature (Arora, Fosfuri, \& Gambardella, 2001; Fosfuri \& Giarratana, 2010). We offer a detailed description of this novel phenomenon. More importantly, this setting is exploited to study fundamental theoretical issues which are critical to the design of an efficient market for ideas (Gans and Stern, 2010). Specifically, we focus on the effect of information asymmetries and expropriation. Within this literature, our study draws on, and relates to, work that is based on principal-agent models (e.g., Arora, 1995; Arora, 1996).

Second, given that the markets for financing entrepreneurial inventions is of limited efficacy (Colombo \& Grilli, 2007), there is room to study alternative settings and institutions 
such as afforded by online marketplaces. The paper presents stylized facts for this novel setting. It, therefore, motivates formal and empirical work on the market for ideas. To that end, we identify theoretical dimensions where the market for ideas differs from that for physical goods, and advance stylized facts on the mechanisms that emerge in this setting. A two sided marketplace for ideas -- unlike a market for physical goods -- may benefit from a low marginal costs associated with the production of intangible goods (Parker \& Van Alstyne, 2005), while at the same time facing the uncertain and skewed value distribution characteristic of such intangible ideas (Scherer, Harhoff, \& Kukies, 2000). We observe that in this setting disclosure of technical information, in addition of pricing strategies, may emerge as important mechanisms that facilitate an idea marketplace. Hence, the paper advances novel stylized facts about pricing and disclosure mechanisms. We believe these insights can inform scholars and practitioners alike.

Finally, and relatedly, the new setting has a potential to widely challenge accepted practices while at the same time substantially expanding the scope of the market for ideas. The online marketplaces represent a qualitative change in the processes that bring knowledge owners (entrepreneurs or inventors) and knowledge seekers (or licensees or investors) together. In our setting, the market facilitates interactions among strangers. This constitutes a sharp departure from accepted practices where transactions tend to materialize around one's geographical area (e.g. Giuri \& Mariani, 2009) and social circle (Kirsch, Goldfarb, \& Gera, 2009; Shane \& Cable, 2002; Ariño, de la Torre, \& Smith Ring, 2005). Extant work finds that social ties prove an effective mechanism in reducing search costs and alleviating adverse selection and expropriation concerns (Coleman, 1990; Fried \& Hisrich, 1994; Hallen, 2007; Shane \& Stuart, 2002). This study investigates how search costs, adverse selection problems and expropriation concerns work in a setting where social ties are not available ex ante and identifies which alternative market 
mechanisms emerge in such a setting. We provide stylized facts on the mechanisms that govern exchanges between anonymous actors in knowledge intensive markets. To the extent that these mechanisms effectively substitute social ties, they can support the creation of new institutions, which in turn would lead to a rapid expansion of the market for ideas (Lamoreaux \& Sokoloff, 2003; Rosenberg \& Birdzell, 1986).

\section{THEORETICAL BACKGROUND}

Extant work identifies factors that shape the markets for knowledge: the cost of searching for quality inventions, adverse selection costs due to high level of information asymmetries, and difficulty in appropriating the value of an invention. We will use the term knowledge owners to denote those who arrive at a market with knowledge assets (e.g., inventors or entrepreneurs). Similarly, the term knowledge seekers denotes those who arrive at a market with the intention to transact with knowledge owners (e.g., potential licensee, acquirers, or interested inventors).

Search Costs. Search costs play a major role in economic decision-making (Stigler, 1961). The term refers to the costs accrued due to the actual search itself, i.e. the cost to "discover who it is that one wishes to deal with and to inform people that one wishes to deal with" (Coase, 1960:7), as well as the foregone payoffs associated with spending time searching (Bakos, 1997). The economic cost of exchanging an asset consists not only of the price of that asset, but also of the search costs associated with finding transaction partners for it. Individuals may undertake acceptable decisions rather than optimal decisions in the presence of high search costs (Simon, 1947). That is, they engage in search patterns that are exhaustive, yet, local. Extending search to more distant alternatives (e.g., beyond one's social circle or one's geographic location) is costly (Sorenson \& Stuart, 2001) and comes with an increasingly higher opportunity cost. Silveira and Amit (2006) show that search costs can have a critical impact on 
one salient knowledge market: the market for venture capital. They argue that an increase in the frequency of meetings between investors and entrepreneurs results in investors finding acceptable investment opportunities faster.

Adverse Selection Problems. Information asymmetries are commonplace in the markets for knowledge and give rise to the adverse selection problem. The owners of innovative knowledge are often best informed of the invention's true quality or potential. In the absence of observable tangible assets (e.g. plants) or established track records, investors or licensees face severe difficulties in evaluating an invention's quality. A malfeasant individual can take advantage of the situation; pose as if she is in possession of high-quality invention. Wary of such opportunistic behavior, investors and licensees may forego relationships altogether. That is, adverse selection problems could lead to market failure (Akerlof, 1970). The fact that only some knowledge assets are valuable (e.g., Gambardella, Harhoff and Verspagen, 2008) implies that adverse selection is of particular concern to participants in the market for innovative ideas (Arrow, 1974; Lemley \& Myhrvold, 2008) and technological breakthroughs (Jensen \& Thursby, 2001).

Expropriation Problem. Protecting one's ownership of an invention is a difficult task. This is the case because of the economic properties of knowledge that make it a public good (Arrow, 1962). Namely, one cannot be easily excluded from using knowledge once it has been revealed. Exacerbating the problem is the fact that the marginal cost of replicating knowledge is often trivial, and it is not depleted when shared. In addition, Intellectual Property Rights (e.g., patents) do not offer complete protection (Arora, 1995; Cohen, Nelson, \& Walsh, 2000; Levin, Klevorick, Nelson, Winter, Gilbert, \& Griliches, 1987). The expropriation problem limits a knowledge owner's ability to capture the value of her invention. If she reveals the knowledge to 
prospective seekers, it may be imitated. And if she chooses not to showcase the knowledge, it could heighten adverse selection problems and lead to market failure.

\section{IMPLICATIONS TO ONLINE KNOWLEDGE MARKETPLACES}

Drawing on the theories above, we review how online knowledge marketplaces benefit from significantly lower search costs, and proceed to discuss what mechanisms a marketplace can adopt to address the substantial increase in adverse selection costs and imitation concerns.

We define online knowledge markets as virtual marketplaces, which facilitate the listing, search and exchange of knowledge assets (Bakos, 1998). By marketplace, we refer to a two sided market, which facilitates matching and efficient distribution of knowledge in a timely fashion (Gans \& Stern, 2010:2). A marketplace connects and facilitates transactions among the two pools of participants: it accommodate those who own and those who seek knowledge assets. The definition excludes 'one-sided' enterprises, such as a university technology licensing offices that features only university-specific inventions. By knowledge assets, we consider various types of intellectual property that are of potential economic value. A patent is one example of a knowledge asset. A business plan that features a novel business model or an opportunity to serve untapped customer needs constitutes another example. By virtual, we consider those knowledge marketplaces whose main presence is online. That is, the initial interaction among market participants takes place through a dedicated online interface on the Internet. Below, we explore the argument that online knowledge marketplaces afford unique benefits while at the same time facing some intense challenges.

Before we do so, it is useful to draw parallels between online knowledge markets and more prevalent virtual two-sided markets such as eBay, Expedia, or Travelocity. Following 
Parker and Van Alstyne (2005), we observe three main groups of players populate these settings. On the one side of the market there are the producers or developers: namely, sellers of baseball memorabilia (eBay), hotels and airlines (Expedia or Travelocity), or inventors, entrepreneurs and other knowledge owners (FlintBox, Yet2, as well as NVST, or vFinance). On the other side there are users or consumers: namely, collectors/buyers of baseball memorabilia (eBay), business and leisure travellers (Expedia or Travelocity), or knowledge seekers such as prospective licensees, commercializing entities, investors (FlintBox, Yet2, as well as NVST, or vFinance). The third group of players, the intermediaries, serve as a platform that connects the two sides.

Online knowledge marketplaces manage platforms (i.e., websites) that accommodate communication, matching, and transacting for innovative knowledge. We note that online knowledge marketplaces are independent entities that are unaffiliated with either knowledge owners or seekers. Many are for-profit companies, while some are not-for-profit ventures. ${ }^{1} \mathrm{~A}$ marketplace is only as successful as its ability to serve as a viable market and support a large volume of transactions. Therefore, it is in the marketplaces' interests to reduce search costs, resolve adverse selection problems, and mitigate expropriation concerns. In other words, it is in the self-interest of an online knowledge marketplace to adopt mechanisms aimed at increasing the ability to achieve efficient trade in innovative knowledge.

Important insights can be gained by studying this latter group of players. As noted earlier, online knowledge markets share may similarities with more ubiquitous online marketplaces such as eBay, Expedia and Travelocity. That said, we believe that important stylized facts and novel theoretical insights can be gleaned by studying the unique conditions in which marketplaces for ideas operate, and the mechanisms they adopt. Unlike a market for physical goods, an online knowledge market benefits from a low marginal costs associated with the production of

\footnotetext{
${ }^{1}$ Not for profit entities may be associated with a foundation (e.g. iBridgeNetwork) or the government (ACE-Net).
} 
intangible goods (Parker \& Van Alstyne, 2005). It also faces challenges associated with the uncertain and skewed value distribution of intangible ideas (Scherer et al., 2000) which critically exacerbates the adverse selection problems experienced in online marketplaces (Ghose, 2009). In this setting, disclosure of technical information may emerge as important mechanisms that facilitate a two sided idea marketplace, in addition of pricing strategies. In what follows, we advance novel stylized facts about pricing and disclosure mechanisms.

\section{Implications to Search Costs.}

There are reasons to believe that online marketplaces lower the cost of searching for knowledge assets. First, online marketplaces afford access to (a) more distant and (b) more diverse audience. An online marketplace also enables its participants to observe and communicate with distant constituencies at a fraction of the cost (Evans and Wurster, 1999; Amit and Zott, 2001). To the extent that broader scope allows one to reach more diverse audience, an online marketplace facilitates connections between parties that could not have been achieved through local, offline, markets. In other words, participants in an online marketplace experience lower search costs. A practitioner technology transfer publication echoes this observation:

“The problem that people have when looking for technology is they can't spend hours on the website of each [Technology Transfer Office] organization in the U.S. or worldwide. They need an interface that provides all of that information, and actually provides a search engine......IP exchanges that offer attractive search tools for the user, such as an ability to cluster similar or related technologies together, are more likely to attract potential licensees (Technology Transfer Tactics, 2008 )”.

Along these lines, many marketplaces emphasize the benefits of search directly or at least highlight the benefits of connecting previously unconnected knowledge owners and knowledge seekers. As such, it may facilitate exposure to new supply or demand for technologies (Zahra, Keil and Maula, 2005; Hall, Thoma and Torrisi, 2009). Consider a testimonial from one marketplace in our sample: 
"The Internet is about a lot of things, but mostly, it's about bridging geographic barriers. Tools like nvst.com are invaluable to small businesses who need to get in front of money people who are geographically scattered." (NVST, 2008)

A broad and diverse participation may be associated with disadvantages, as well. Although participants benefit from reduced search cost, they may have limited time or capacity to inspect the abundance of prospective knowledge assets. The broad inclusion afforded by online marketplaces may attract owners of high-quality inventions, but might also be populated by useless ideas. The problem is exacerbated because knowledge owners can remain anonymous when posting an invention or business plan. Thus, the feature which allows online marketplaces to reduce search costs, may, unintentionally, exacerbate adverse selection.

Second, online marketplaces further reduce search costs by offering standardised representation of information. Knowledge available on the websites is codified in a standardised way which facilitates the search and exchange of information (Teece, 2000). Participants can communicate more effectively because they have a common language in the form of templates provided by the marketplace. A quote from Yet2, another marketplace in our sample, exemplifies the benefits due to these data requirements:

"Because patent abstracts are designed to protect an idea from infringement, they obscure the technology, making it difficult for potential buyers to imagine relevant applications. Conversely, Yet2 features functional abstracts written in plain English to communicate the potential applications and benefits of the technology." (Yet2.com, 2008a).

It follows that the use of online communication templates reduces search costs. However, it is not without disadvantages: specifically, increasing the likelihood of imitation (Rivkin, 2001; Winter, 1987). In other words, codification - a feature of online marketplaces that leads to reduced search costs - may inadvertently increase expropriation problems.

\section{Implications to Adverse Selection Problems.}


The advantage of lower search costs may be overshadowed by heightened adverse selection costs and expropriation risk. Unresolved, the problems may lead to a breakdown of the market for ideas. Moreover, there are reasons to believe that online markets are particularly sensitive to market failure. A case study of Patent \& License Exchange (PL-X), a pioneering knowledge marketplace which was launched - and closed - in the late 1990s, comments:

"Asymmetry of information between buyer and seller, and the possibility of infringement and 'junk patents' (i.e., invalid or unenforceable patents) were among novel risks confronting IP market players. Furthermore, processes that offered to mitigate these risks were difficult or impossible via the web. Although most critics agreed that the web facilitated searches and bulletin boards, many believed this was the extent of its possible value (Chesbrough \& Smith 2000:5)... Indeed, maintaining the integrity and credibility of the market was essential to its long term success since poor selection, whether due to low quality patents or subversive uses, would increase the risk for credible players" (Chesbrough \& Smith 2000:10).

If we observe an active marketplace, it stands to reason that it has devised mechanisms that offer viable solutions to the above problems. Extant work indentifies several mechanisms that alleviate adverse selection problems. Entrepreneurs and inventors may be required to agree to a contingent payment scheme. Alternatively, they may have to reveal their knowledge asset.

The former mechanism, a contingent payment scheme, describes a scenario whereby a knowledge owner attempts to attract knowledge seekers by agreeing to make her payoff contingent on the quality of the knowledge (Leland \& Pyle, 1977; Silveira and Wright, 2010). Accepting such an arrangement is not profitable for an individual with a useless invention. ${ }^{2}$ Thus, an individual who is willing to make her payoff contingent on success, leads investors to infer that she holds a useful invention (Lazear, 1999). By analogy, online marketplaces may opt to levy an initial cost on participants. Imposing such a fee has the effect of linking a knowledge owner's payoff to the quality of her invention. Accepting such an arrangement is not profitable

\footnotetext{
${ }^{2}$ Preferred shares, which are ubiquitous in the venture capital markets, are an example of a contingent payment mechanism. By allocating cash-flow priority to VC investors, an entrepreneur earns a positive payoff in the case of success but receives no payments in the case of failure (Kaplan \& Strömberg, 2004; Sahlman, 1990).
} 
for those with a useless invention. As a result, only those with useful knowledge assets will choose to pay the fee and join the marketplace. In other words, imposing a cost on entrepreneurs and inventors will have the effect of mitigating adverse selection problems.

The second mechanism, disclosure, denotes a scenario where a knowledge owner reveals detailed information. Prospective investors and licensees evaluate the knowledge and, if their assessment is positive, consummate a transaction. Common disclosure strategies include the provision of a complete set of blueprints or laboratory notes, or a demonstration of a service (e.g. Anton \& Yao, 1995; Gans \& Stern, 2003; Zott \& Huy, 2007). Disclosure allows market participants to negotiate on the basis of full, rather than asymmetric information. That is, by allowing others to directly assess her knowledge, an individual with a useful invention eliminates adverse selection concerns and may proceed to capture its full value.

If adverse selection poses a critical hurdle to marketplace efficacy, one would expect marketplaces to attempt and mitigate it. Put differently, a marketplace that does not resolve adverse selection problems would find it difficult to attract participants and may ultimately disappear. Thus, we conjecture that mechanisms such as disclosure and contingent payment would be adopted by existing marketplaces.

\section{Hypothesis 1: In online knowledge marketplaces, disclosure and contingent payment requirements would be common.}

Next, we derive specific hypotheses regarding each of the mechanisms. First, consider the contingent payment requirement that is levied on knowledge owners. One might argue that the reason for the upfront fee has little to do with adverse selection. Rather, the fee is merely a mean by which an online marketplace profits: namely, a marketplace charges participants in order to sustain its own operations. We believe that this claim has merit, yet emphasize that the identity of the parties subjected to an upfront fee is in line with the logic of adverse selection 
mitigation. Note that the cost is levied on the cash-starved entrepreneurs or inventors rather than the affluent investors or licensees. We elaborate on this point and derive a testable hypothesis.

In online knowledge marketplaces both market participants benefit from reduced search costs. As self interested entities, online marketplaces attempt to maximize their own revenue, charging participants for the right to be part of the marketplace. Entrepreneurs and inventors would pay to increase their chances of finding knowledge seekers. Similarly, investors and licensees would pay to enhance the likelihood of finding valuable knowledge assets.

To the extent that both parties benefit from their participation in the marketplace, we expect that they would be subjected to similar payment requirements. Bakos (1997) highlights that online markets reduce buyer search costs: hence it is knowledge seekers that should have higher incentives to pay. Moreover, in our particular setting, investors and licensees are usually endowed with capital and thus have the financial capacity to pay upfront fees. Thus, knowledge seekers may have a greater inclination as well as a greater capacity to pay upfront fees.

Nonetheless, marketplaces could choose to impose a fee requirement on knowledge owners. This may be the case since a fee requirement mitigates the adverse selection problem: it deters those with useless inventions from participating in the marketplace. Anecdotal evidence illustrates that such a mechanism is geared towards increasing the average quality of the pool of participating knowledge owners:

“Application and presentation fees weed out entrepreneurs who aren't serious and prevent deal spammers, they also provide added income (Pipkin R - East Coast Account Manager Angelsoft, 2008).”

More broadly, marketplaces admit that they profit from charging upfront fees, yet emphasize that fees are levied on knowledge owners. Consequently, fees act as a screening mechanism and assure knowledge seekers that participation is limited to those with quality knowledge assets: 
"Many people have asked us why we charge entrepreneurs for the service. Firstly we are running a commercial enterprise and don't get any public funding... Secondly we are providing a valuable service to the entrepreneurs who need the support to get their ideas in front of investors. To set up a serious business with outside funding you do need to be prepared to spend some money (Angel Investment Network, 2008, italics added).“

Because adverse selection problem arises due to information asymmetry about inventions' quality, the problem is addressed by imposing upfront fee specifically on knowledge owners. Hence, we expect fee requirements to be directed towards entrepreneurs and inventors.

Hypothesis 2: In online knowledge marketplaces, upfront fee requirements are more likely to be imposed on knowledge owners rather than knowledge seekers. Implications to Expropriation Problems.

We shift our attention to the second mechanism: disclosure. Online marketplaces require knowledge owners to reveal information, so that knowledge seekers could assess knowledge assets directly and avoid any postings of assets of questionable or low quality. Raisecapital.com, a marketplace enforcing disclosure, explains:

"We encourage you to include as much information as possible in your post. This can only increase the likelihood of having your venture funded. Posts that are confusing or do not explain your business idea or capital needs in a meaningful fashion may be rejected." (email communication with RaiseCapital.com).

Disclosure is not a panacea, however. The mechanism may mitigate adverse selection costs for knowledge seekers, yet, it may result in imitation of knowledge owners' inventions. (Arrow, 1962). If imitated, knowledge owners risk appropriating little or none of the value of the invention (Anton \& Yao, 1995, 2005; Gans \& Stern, 2003). It follows that the efficacy of disclosure is sensitive to moral hazard by knowledge seekers: the greater the likelihood they will exploit disclosed information and imitated knowledge owners, the less likely disclosure can be adopted as an effective mechanism to facilitate online knowledge markets. Anecdotal evidence suggests that online knowledge marketplaces are aware of the ensuing moral hazard problem: 
"However, there should not be any disclosures that would allow someone to misappropriate your idea. If you have such concerns, then once an investor contacts you, you might want to consider asking him/her to sign a confidentiality or non-disclosure agreement before you fully reveal your product or business idea in full detail." (RaiseCapital.com, 2008)

Various factors determine the efficacy of the disclosure mechanism. For example, the prevailing legal environment may award strong protection to knowledge owners and thus circumvent imitation. Alternatively, knowledge owners may possess unique and tacit know-how that is critical to successful commercialization. They may be more inclined to pursue a disclosure mechanism under those conditions that allow them to credibly withdraw their support. Hypotheses 3 and 4 conjecture regarding marketplaces' adoption of a disclosure mechanism as a function of the legal environment and tacit knowledge, respectively.

Consider the role of the legal environment. We identified earlier that the risk of imitation is particularly salient in online knowledge marketplaces, where knowledge owners codify and list their inventions to facilitate searches of disclosed inventions by anonymous knowledge seekers. Disclosure, however, does not necessarily result in imitation. Rather, the likelihood of imitation is affected by the prevailing regime of Intellectual Property Right (IPR) (Teece, 1986). For instance, a patent is a well recognized mean of IPR protection which gives knowledge owners monopoly rights over their inventions.

To the extent that certain online marketplaces exhibit a higher level of patent protection, one would expect to observe variation in the practice of disclosure. In our sample we identify two distinct types of marketplaces which we term Venture Capital Markets (VCM) and Intellectual Property Markets (IPM) (see definitions below). Of relevance to the current discussion is the fact that VCMs and IPMs differ in the degree of patent protection. The innovative knowledge in VCMs tends to be in the form of business plans, whereas IPMs usually 
involve patented knowledge assets. Therefore, the latter may be less susceptible to imitation than the former. Knowledge owners who participate in IPMs may be more inclined to adhere to disclosure requirements than their counterpart in VCMs. Put differently, VCMs are less likely to hold owners to strict disclosure requirements. We thus hypothesize that disclosure will be common in marketplaces that trade protected knowledge assets;

\section{Hypothesis 3: Disclosure requirements are more likely to be employed in Intellectual Property Marketplaces (IPM) than in Venture Capital Marketplaces (VCM).}

Next, consider the role of tacit knowledge. Knowledge owned by inventors and entrepreneurs alike contains a codified and tacit part (Arora, 1995; Winter, 1987). Tacit knowledge is personal to the inventor and entrepreneur who can choose when and towards whom to reveal it. Prior work indicates that tacitness plays a critical role in knowledge owner's ability to appropriate the value of his or her invention (Jensen \& Thursby, 2001; Lowe, 2001).

Tacit knowledge is particularly critical to rent appropriation in settings where Intellectual Property Rights are incomplete (i.e., patents afford only partial protection of codified knowledge). Arora (1995) articulates the conditions for successful appropriation: the knowledge seller must retain the provision of tacit knowledge, and tacit and codified knowledge must be complementary. Indeed, in settings as project consulting (Agrawal, 2001) or entrepreneurial financing (Stuart, Hoang, \& Hybels, 1999), it is common to observe two tariff contracts, in which knowledge seekers pay first for the codified part and later pay for the tacit part.

These conditions characterize the VCM setting. We conjecture that knowledge sellers will be inclined to utilize a disclosure mechanism in venture capital marketplaces. The reason is twofold. First, the ongoing input and advice of knowledge sellers is critical to the successful growth and deployment of knowledge assets, such as business plans and entrepreneurial ideas, 
which are traded in VCMs. In contrast, the assets traded in IPMs (namely, granted patents) are well defined and therefore require less ongoing input based on sellers' tacit knowledge.

Second, the profile of knowledge seekers may further drive our conjecture. Knowledge seekers that participate in IPMs are often medium and large corporations. They possess R\&D, manufacturing and commercialization facilities and consequently are less dependent on sellers' ongoing advice. Conversely, the participants in VCMs include corporations as well as individual or institutional financial inventors. One VCM explains that participating knowledge seekers are accredited financial investors (e.g., wealthy individuals) who pose lower risk of expropriation:

"...are wealthy individuals who have already made their money and are now looking to invest in startup companies. They are not looking to startup another business, and therefore not interested in stealing your idea (Angelsoft, 2008)."

In other words, financial investors exhibit lower inclination to pursue imitation. Also, they have fewer facilities and lesser commercialization experience and hence are more dependent on the tacit knowledge of the entrepreneur. Whereas knowledge owners in VCMs remain a key factor in the commercialization process, knowledge seekers in IPMs are likely better equipped to commercialize invention independent from the knowledge owner.

Following Arora (1995), we conjecture that in VCMs knowledge owners possess unique tacit knowledge that seekers find crucial to the successful deployment of knowledge assets. Namely, entrepreneurs in VCMs would be willing to disclose their codified knowledge, as they also possess tacit knowledge, without which the invention or business plan is incomplete.

\section{Hypothesis 4: Disclosure requirements are more likely to be employed in Venture Capital Marketplaces (VCM) than in Intellectual Property Marketplaces (IPM).}

To conclude, we conjecture that the adoption of a disclosure mechanism is shaped by the impact of disclosure on seller's rent appropriation. The less likely disclosed information will be expropriated, the greater the probability a marketplace will adopt a disclosure mechanism. There 
are several theoretical factors that are associated with the decision, including the strength of the IPR regime, the complementarity between tacit and codified knowledge, and the ability of knowledge sellers to withdraw their support (Anton \& Yao, 1995; Arora, 1995; Arora et al., 2001; Arrow, 1962; Parker \& Van Alstyne, 2005). We use category affiliation to proxy for these effects: IPMs are associated with the former (i.e., IPR regime), while VCM are associated the latter factors (i.e., tacit-codified complementarities, knowledge withdrawal).

\section{DATA, SAMPLE AND MARKETPLACE FEATURES}

\section{Identifying Online Knowledge Marketplaces}

We identify thirty websites fulfilling the criteria of online knowledge marketplaces outlined above. They fall into two categories: the Venture Capital Marketplaces (VCM) category and the Intellectual Property Marketplace (IPM) category.

Venture Capital Marketplaces (VCM) connect entrepreneurs and investors. Entrepreneurs post their ideas in form of business plans. Investors can search these entries and select which one to fund. A few VCMs serve as a marketplace between nascent entrepreneurs and angle investors (e.g., Angel Investment Network) whereas other VCMs include more mature businesses (e.g., NVST). One commonality across all VCMs is the fact that entrepreneurs list their ideas in the form of a business plan.

Intellectual Property Marketplaces (IPM) connect inventors who list patents for licensing or alternative collaborative arrangements (e.g. joint ventures) and potential licensees or investors who can search the listed information online. One of the most prominent marketplaces in this category is Yet2 which was founded in 1999 by a consortium of multinational firms. A few IPMs predominantly draw patents from universities or public research institutes (e.g. Flintbox and 
iBridgenetwork) whereas others also pool patents from the private sector (e.g. TechTransferOnline or Yet2).

Below, we describe the procedure used to identify online knowledge marketplaces. We then proceed to explain the similarities that Venture Capital and Intellectual Property marketplaces share, as well as the key differences between the two categories. Table 1 lists all 30 marketplaces and their designated category.

Insert TABLE 1 about here.

An extensive two-stage search procedure was undertaken to identity online knowledge marketplaces. First, we query numerous databases (e.g., ABI Informs, Google, Lexis Nexis, Proquest) for related information published in the business media during the period 1998-2008. The queries consisted of various permutations of the following keywords: (online, electronic, Internet), and (marketplace, market, platform, exchange), and (entrepreneur, innovation, invention, technology, knowledge). This search generated an initial list of established online knowledge marketplaces, some of which already received scholarly attention, such as Yet.2com (Lichtenthaler, 2005) and ACE-Net (e.g. Acs \& Tarpley, 1998). Next, we use the names in the initial list as search terms, and re-queried the aforementioned databases. This second round of searches proved particularly productive because news articles often mention more than a single marketplace. The procedure yields a list of fifty seven potential online knowledge marketplaces.

To enter our final sample, a marketplace has to satisfy several criteria. First, it has to serve as a two-sided market for knowledge assets. Specifically, a marketplace should connect two pools of participants where one side lists their knowledge assets and the other side can search and transact for those assets. Accordingly, we exclude 'one-sided' universities' websites aimed at technology/knowledge transfer of own invention (e.g. MIT's and Harvard's technology 
licensing office ${ }^{3}$ ), as well as websites that are dedicated to the commercialization of governmentsponsored inventions (e.g. the USA Department of Defence ${ }^{4}$ ). Those websites do not fulfil the two-sided criterion: while they are open for knowledge seekers they only list information from a single knowledge owner (i.e., the sponsoring university or the Department of Defence). Similarly, we excluded directories that are limited to a 'one-sided' list of either knowledge owners (e.g., Delphion ${ }^{5}$ ), knowledge seekers (e.g. Venturedeal ${ }^{6}$ publishes a list of potential inventors) or information about prior exchanges (Grow Think Research ${ }^{7}$ ). Rather than acting as a marketplace, those websites feature only one side of the market. Delphion, for example, offers a comprehensive patent database. It automatically covers all granted patents, thus allowing knowledge seekers to search all knowledge assets. Yet, and offers no parallel function for knowledge owners who wish to find relevant knowledge seekers.

Second, we impose a quality hurdle. A two tier quality filter is utilized to avoid the inclusion of 'one man show' or even fraudulent websites. To that end, we exclude any websites which were not mentioned in a major credible business source. A marketplace enters our sample only if it was mentioned at least once in an article covered by Lexis Nexis, Proquest or ABI Informs. Also, we read all news articles to further ascertain marketplace quality (e.g., it was not mentioned as a scam). In total, 19 websites did not meet the requirements of our quality filter and were excluded from the analysis.

Finally, we consider only online marketplaces that were active in 2008 . The sample is limited to active marketplaces to allow data collection on marketplace structure and the mechanisms they employ. The final sample consists of thirty online knowledge marketplaces.

\footnotetext{
${ }^{3}$ www.web.mit.edu/tlo/www/, www.techtransfer.harvard.edu

${ }_{5}^{4}$ www.dodtechmatch.com, www.techlinkcenter.org

${ }^{5}$ www.delphion.com

${ }^{6}$ WwW.venturedeal.com

${ }^{7}$ www.growthinkresearch.com
} 


\section{Venture Capital Marketplaces (VCM) and Intellectual Property Marketplaces (IPM)}

Two marketplace categories emerge as we conducted our searches. Our initial goal was to identify websites that operated two-sided markets for innovative knowledge. As we inspected the initial list of marketplaces, it became apparent that each marketplace falls within one of two categories: a VCM or an IPM. The two categories differ on several dimensions yet are similar on other dimensions.

One reason that led us to point to two distinct categories is the way in which marketplaces were set apart by the business media. During the initial construction of the sample, we observed that certain marketplaces were regularly discussed within the same news article, while others were rarely mentioned in the same article. Based on these observations, we proceeded to conduct hundreds of search permutations for the marketplaces in our sample. ${ }^{8}$ The analysis suggests that the two categories are mutually exclusive: there is not a single instance in which a VC and IP marketplaces are mentioned in the same news article.

Another dimension on which VCMs and IPMs differ is the identity of the participants. Intellectual Property Marketplaces feature listings mainly by large corporations, universities, or the government. Conversely, Venture Capital Marketplaces are predominantly used by individual entrepreneurs who list their business ideas. Thus, when it comes to the identity of the knowledge owners, VCMs and IPMs draw on different pools of participants.

Finally, a handful of websites could be categorized as VCM as well as IPM (e.g. Ideaconnection, VC-capital.com). Interestingly, these websites clearly differentiate between the IPM and VCM feature. For instance, the website Ideaconnection distinguished between technologies for license or sale (IPM) and business ideas for funding or sale (VCM). Each one

\footnotetext{
${ }^{8}$ Multiple LexisNexis searches were run to determine whether any of the VC and IP marketplaces ever appeared in the same news article. In total we examined 16 (VCM) x 14 (IPM) possible combinations. We excluded two searches of online markets that offer VCM and IPM on a single website (i.e. Ideaconnection and v-capital).
} 
had a different entry interface on the Ideaconnection website. Moreover, Ideaconnection required different templates to be filled in, depending on whether it was a patent or a business plan. It indicates that marketplace operators themselves view VCM and IPM as two distinct categories.

Although VCMs and IPMs exhibit many differentiating features, we believe that they can be studied together. Both serve as online knowledge marketplaces. Indeed, as noted in the previous paragraph, several website operators chose to offer an IPM feature along with a VCM feature. This observation suggests that mechanisms that prove effective in facilitating one type of a marketplace may also prove useful in the context of the other type of a marketplace.

More broadly, there is a degree of overlap in the nature of assets traded in these marketplaces. For example, a prominent IPM, Yet2, requires inventors to denote whether they seek venture funding (a key focus of VCMs). Also, 25\% (4 out of 16) VCMs explicitly ask knowledge owners, whether patents (a key focus of IPMs) or other forms of intellectual property are at the base of the business plan. To conclude, there is strong evidence that although VCMs and IPMs exhibit unique features, they are not polar opposites and can be studied together as representing online knowledge marketplaces.

\section{Identifying Key Features of Online Knowledge Marketplaces}

Guided by the theory, we look for evidence of mechanisms that mitigate adverse selection and expropriation concerns. Specifically, we detect two mechanisms adopted by the marketplaces: a contingent-payment-screen and a disclosure-screen ${ }^{9}$.

Contingent Payment Screen. An online knowledge marketplace is considered to adopt a contingent-payment-screen if a participant is required to pay an upfront fee. A participant who paid an upfront fee can profit if and only if the knowledge assets is useful. It therefore deters those who consider posting useless listings. It follows that the advantages of a fee requirement

\footnotetext{
${ }^{9}$ Information was collected between the Fall 2008 and Spring 2009.
} 
are twofold: (a) it limits the amount of listings to useful knowledge assets, and (b) serves as a signal of quality to prospective knowledge seekers (Amit, Glosten, \& Muller, 1990). Two researchers independently coded whether a marketplace requires upfront fees using websites' screenshot. Inter-rater reliability was $88 \%^{10}$. For the remaining $12 \%$ both researchers discussed and reviewed the documentation together to clarify all remaining issues.

Disclosure-Screen. A marketplace may choose to reject an entry submitted by a knowledge owner. Prior to listing a submitted entry, the marketplace ensures that the listing includes sufficient details. That is, a marketplace may enforce disclosure requirements on knowledge-owners with the objective of enabling knowledge-seekers to accurately evaluate the knowledge. Absent a disclosure-screen, any knowledge assets might have been published on the marketplace, irrespectively of its quality or detail. A disclosure-screen facilitates informed assessments and consequently reduces information asymmetries between the participants. It therefore reduces the probability that low quality proposals will be listed on the marketplace.

To establish the presence of a disclosure screen, the following steps were undertaken. For each marketplace, we took the role of a knowledge owner and submitted rudimentary application. The submission deliberately excluded details about the invention. Below are communications from several marketplaces in response to our rudimentary submissions.

Dear ..., We're sorry, but your Funding Profile, ..., has been denied for the following reason. This is not enough information to have an active profile on IdeaCrossing. It will remain rejected and in an inactive state until you provide the required information. You may review and revise the information that you submitted for reconsideration." (email Ideacrossing, 2008)

Thank you for submitting your post to RaiseCapital.com. However, we cannot approve your post at this time. Your post only contains a few sentences and/or does not describe in great detail your business idea or capital needs for your business. A potential investor is going to want to see as much information as possible in order to have an interest in

\footnotetext{
${ }^{10}$ The level of agreement includes the disclosure screen, which is discussed below.
} 
your venture. A vague and non-descriptive post will not attract a "real investor". (email Raisecapital, 2008)

An online knowledge marketplace is considered to adopt a disclosure-screen if our submission results in a rejection note as listed above. Even if a rejection note is not generated, we assume a marketplace adopts a disclosure-screen if a submission is not subsequently listed online. ${ }^{11}$

\section{ANALYSIS}

We present evidence on the mechanisms online knowledge marketplaces employ. Table 2 delineates the frequency of each mechanism, broken by marketplace category.

-Insert TABLE 2 about here.

Overall, $90 \%$ (27 out of 30) of the marketplaces in our sample adopt a screening mechanism. At first glance, this practice seems at odds with marketplaces' own best interests -- it can significantly limit traffic to the marketplace. Recall that one of the distinct features of an online marketplace is the ability to generate a large volume of participants. That is, online marketplaces have an incentive to grow volume fast and reach a critical scale (Bakos, 1998; Katz \& Shapiro, 1994). Accordingly, one might expect that a marketplace would have little incentives to employ screening mechanisms which limit the number of participants. Indeed, this intuition is consistent with the observation of commodity marketplaces such as eBay and Amazon, which do not charge an upfront fee to sellers. ${ }^{12}$ Yet, in the case of online knowledge marketplaces a large majority of firms impose screens on knowledge owners.

We test a null hypothesis that online knowledge marketplaces do not employ any screening mechanism. Using a chi-square goodness of fit test, the null hypothesis is rejected

\footnotetext{
${ }^{11}$ The results are robust to the exclusion of these marketplaces.

${ }^{12}$ In the case of $e$ Bay, sellers are not required to pay upfront fees as long as they initiate 100 auctions of less. Note that in the context of online knowledge marketplaces, knowledge seekers may perceive adverse selection costs to be very high when faced with knowledge owners with no history of successful inventions.
} 
indicating that the usage of screening mechanism (either contingent-payment or disclosure) in online knowledge marketplaces is highly significant $\left(\mathrm{Chi}^{2}=24.3, \mathrm{p}<0.001\right)$. This finding is in line with our contention that screening mechanisms are widespread in online marketplaces, which supports Hypothesis 1.

Interestingly, even nascent marketplaces (i.e., those established in 2007 or 2008) attempt to mitigate adverse selection. Seven out of eight (i.e. $87.5 \%$ ) of these young marketplaces employ some form of a screening mechanism. These mechanisms have the advantageous effect of mitigating adverse selection problems, yet they may limit the number of knowledge owners that ultimately participate in the marketplace. Note that nascent marketplaces are particularly in need of reaching a critical mass of participants and are therefore less likely to undertake actions that restrict the number of business plans and inventions posted onto their websites. Nonetheless, the evidence suggests that newly established marketplaces do employ contingent payment and disclosure mechanisms. Overall, the findings are in line with our contention that screening mechanisms are widespread in online marketplaces, supporting the idea that online knowledge markets try to mitigate adverse selection.

Looking at all 30 marketplaces, we further observe that they are more likely to adopt contingent-payment-screens rather than disclosure-screen. Using the Mann-Whitney-Wilcoxon (MWW) nonparametric test, we indeed find that the former is more likely than the latter $(\mathrm{z}=$ 3.345, $\mathrm{p}<0.001) .{ }^{13}$ Arguably, the finding reflects that upfront fees are also an important source of marketplace's revenue. Put differently, the contingent-payment mechanism gives a marketplace

\footnotetext{
${ }^{13}$ The Mann Whitney Wilcoxon (MWW) test checks for differences in the distribution of two random vectors. It is non-parametric and distribution free, and hence appropriate when the underlying distribution is non-normal, or the sample size is small. The MWW has been employed in the literature to test for differences in the perceived value of patents across inventors and managers (Gambardella, Harhoff, Verspagen, 2008), compare between the innovation characteristics of electricity and other technologies (Moser and Nicholas, 2004), as well as between public and private equity back companies (Stuart and Yim ,2010).
} 
an opportunity to alleviate adverse selection while simultaneously maximizing its own proceeds. Interestingly, the three not-for-profit websites fall in line with the predictions of hypothesis 1 . This observation suggests that the mitigation of adverse selection is a key driver for the adoption of the contingent-payment-screen.

To further explore the topic, we test Hypothesis 2. Specifically, we investigate who is subjected to the contingent-payment-screens: the knowledge owners or the knowledge seekers? Table 3 delineates the frequency of the mechanism, broken by participant type and marketplace category. We observe that although knowledge seekers tend to be cash-rich, they are not required to pay upfront fees. Conversely, the cash-starved knowledge owners often have to make upfront payments to list on the marketplace. In line with Hypothesis 2, this observation suggests that contingent-payment-screens are adopted to deter low-quality knowledge owners from participation in the marketplace. That is, the mechanism mitigates adverse selection concerns. Anecdotal evidence further corroborates our interpretation. Quotes presented in the discussion leading to Hypothesis 2 illustrate that contingent-payment-screens do indeed cover marketplace's administrative costs but play an instrumental role in strengthening the perception that the pool of participating knowledge owners is of high quality.

We subject these observations to rigors testing. Using the Mann-Whitney-Wilcoxon (MWW) nonparametric test, we test a null hypothesis that the different participants face similar fee requirements. The test indicates that the null hypothesis is rejected: the difference in fee requirements for owners and seekers of innovative knowledge is highly significant (z-stats = $3.895, \mathrm{p}<.001)$. This pattern holds for IP as well as VC marketplaces. The clear and statistically significant off-diagonal pattern of Table 3 is consistent with the predictions of Hypothesis 2. As noted in the discussion leading to the hypothesis, the way in which marketplaces adopt a 
contingent-payment-screen allows them to mitigate adverse selection while simultaneously covering their ongoing expenses.

-Insert TABLE 3 about here.

We shift our attention to the second mechanism: disclosure. Disclosure may mitigate adverse selection by allowing knowledge seekers to directly evaluate inventions, yet it also leaves knowledge owners vulnerable to imitation and expropriation. The lower the probability that disclosure results in imitation, the greater the likelihood a disclosure mechanism is adopted by online knowledge marketplaces. Hypotheses 3 and 4 make contrasting predictions regarding the prevalence of a disclosure mechanism across the two marketplace categories.

Hypothesis 3 predicts the prevalence of disclosure mechanisms as a function of the legal environment. To the extent that knowledge assets traded in IP marketplaces (namely patents) enjoy stronger legal protection, a disclosure mechanism should be more common in IPMs than in VCMs. Hypothesis 4 focuses on the adoption of disclosure mechanisms as a function of the tacit knowledge. To the extent that ongoing input and advice of knowledge sellers is critical to the success of knowledge assets traded in VC marketplaces (namely business plans and entrepreneurial ideas), a disclosure mechanism should be less common in IPMs than in VCMs.

Anecdotal evidence indicates that imitation is indeed a major concern that shapes participants' inclination to adhere to disclosure requirements. Twelve out of thirty marketplaces (39\% of all VCMs and $44 \%$ of all IPMs) advance detailed discussions on the topic of imitation and the risk of expropriation ${ }^{14}$. The discussions underscore the salience of expropriation concerns in online markets for knowledge. For example, IPMs often provide templates for non disclosure agreements, so that knowledge owners can prepare for an appropriate disclosure strategy. VCMs

\footnotetext{
${ }^{14}$ Based on the business descriptions and "frequently asked questions - FAQ" sections of the marketplaces.
} 
also address the risk of imitation. One marketplace advises knowledge owners on how to "safeguard" an invention so "no one takes it as their own" (Ideacrossing, 2008).

The aforementioned anecdotes emphasize the role of expropriation concerns yet do not inform which marketplace category sees greater adoption of the disclosure mechanism. The answer to that question is provided in Table 2: $31 \%$ of the VCMs adopt a disclosure-screen compared to only $14 \%$ of the IPMs. That is, VCMs are more likely to adopt a disclosure mechanism. These patterns seem to be consistent with Hypothesis 4. However, the differences are not statistically significant. We test the null hypothesis that VCM and IPM exhibit the same pattern of active screening mechanism. A Mann-Whitney-Wilcoxon (MWW) nonparametric test finds that the null hypothesis cannot be rejected, indicating that the difference between VCM and IPM is not statistically significant ( $\mathrm{z}$-stats $=1.078)$.

A potential interpretation of the findings is that that there are multiple forces which lead knowledge owners to disclose their ideas. These, seemingly opposite, forces are at play simultaneously. Whereas knowledge owners in IPMs would disclose their inventions because they possess strong property rights for their intellectual property (i.e., patents), knowledge owners in VCMs might be willing to disclose their business ideas because they possess substantial tacit knowledge which reduces the risk of expropriation. An alternative explanation may allow that VCM/IPM affiliation is a course proxy for the effect of legal environment and tacit knowledge. Above all, the results stress the need for future investigations of the drivers of disclosure mechanism adoption.

\section{DISCUSSION AND CONCLUSIONS}

It is well accepted that $e$ Bay is the primary online market for physical assets. Yet, we do not see a similarly dominant entity in the space of online knowledge marketplaces. This 
observation, in and by itself, suggests that there are unique challenges associated with enabling the market for ideas. In other words, there is a need for effective marketplaces and institutions that can support the knowledge economy. We believe that the mechanisms identified in this study can advance our understanding on how to address this need.

Extant work suggests that knowledge has unique characteristics that hinder the speedy and efficient transfer (Grant, 1996; Nelson \& Winter, 1982; Teece, 1977; Winter, 1987; Gans and Stern, 2010). We advance several stylized facts. Specifically, our study investigates mechanisms that assuage these challenges in the context of online knowledge marketplaces. Drawing on theoretical insights, we note that adverse selection is a major friction in the exchange of knowledge in general, and in online marketplaces in particular. We find that an overwhelming proportion of online marketplaces require entrepreneurs and inventors (i.e., knowledge owners) to disclose their inventions and/or to make upfront fees as prerequisite for participation. Both mechanisms alleviate adverse selection and thus attract prospective investors and licensees.

We believe our findings assist in understanding the effect of these factors in a novel setting for open innovation (Chesbrough, Vanhaverbeke, \& West, 2006): the context of online markets for knowledge. It, therefore, adds to extant work which has pointed to relationships of firms with academic and government labs (Cohen et al., 2002; Laursen \& Salter, 2004), strategic alliances (Gulati, 1995; Hagedoorn \& Schakenraad, 1994; Powell, Koput, \& Smith-Doerr, 1996), and equity investments (Dushnitsky \& Lenox, 2005).

As for the contingent-payment-screen, we find that upfront fees are imposed on knowledge owners rather than knowledge seekers. This observation is surprising given that members of the latter group usually enjoy greater capital endowment and stand to benefit from 
the lower search cost afforded by the marketplace (Bakos, 1998). We show that this finding is consistent with the logic of adverse selection mitigation.

As for the disclosure-screen, we find that the adoption of this mechanism does not vary significantly between VC and IP marketplaces. We attribute this finding to the fact that disclosure mechanism may be adopted for diverse reasons: stronger protection of codified knowledge is particularly important in IPMs, whereas the contribution of owner's tacit knowledge is plays a significant role within VCMs. In other words, disclosure mechanism is equally important across marketplace categories, yet for different reasons.

We note that the mechanisms identified hold not only for the majority of for-profit marketplaces, but also for the not-for profit marketplaces and nascent online knowledge markets. Second, our sample includes several long term players in this space (e.g., Yet2 founded 1999, and NVST founded 1996). The fact that surviving marketplaces adopt these mechanisms may further allude to the instrumental role that contingent-payment and disclosure screens play in facilitating the market for ideas.

There are several avenues for future research. Future work could go beyond the VCM IPM dichotomy and construct finer grained measures of IP rights variable. These measures could draw on industry affiliation as a proxy for the appropriation regime (Teece, 1986). Subsequent studies can expand the analysis to other related marketplace categories. There are a number of online marketplaces which facilitate an 'inverse' knowledge brokering cycle (Hargadon \& Sutton, 1997): knowledge seekers define a problem, which is subsequently solved by a group of experts. InnoCentive represents an established 'problem solving' website, and has been subjected to some scholarly work (Jeppesen \& Lakhani, 2009; Verona, Prandelli, \& Sawhney, 2006). Indeed many of our online knowledge market websites have started offering such problem 
initiated searches. Studying how the mechanisms of online knowledge markets, which we have explored in this study, apply to such 'problem solving' websites could reveal further insights on the nature of online interactions between the market participants and how they facilitate exchange of knowledge. Finally, future research could examine the interaction between market mechanisms and participants' characteristics. For example, the extent to which optimism shapes participants interactions (e.g., Dushnitsky, 2010). Alternatively, information asymmetries and expropriation concerns might be affected by the reputation of knowledge owners and knowledge seekers using the marketplace (Fosfuri \& Giarratana, 2010) such that subsequent work could explore whether large corporations and research universities can substitute reputation for disclosure or contingent payment mechanisms.

Online knowledge markets also have several practical implications for managers. For operators of knowledge marketplaces, the upshot is twofold. First, a somewhat counter-intuitive implication is that operators should limit access to the marketplaces. Free access could result in the erosion of the average quality of participating knowledge owners and ultimately to market failure. Second, there are several mechanisms that a market operator can utilize to limit and manage participation. We discuss the role of disclosure and upfront fees requirements. For example, requiring upfront fees from cash-constrained knowledge owners may have the effect of maintaining the average quality high and thus attracting knowledge seekers. It also provides valuable revenue stream to market operator.

There are also takeaways for knowledge owners. Online knowledge markets provide an alternative route to access complementary resources to commercialize inventions and ideas (Teece, 1986). One of the scarcest resources for entrepreneurs is capital. This is particularly salient for a growing fraction of entrepreneurial ideas, which are neither served by venture 
capitalists or angel investors nor are able to attract large scale bank financing (Colombo \& Grilli, 2007; Fishback, Gulbranson, Litan, \& L. Porzig, 2007; Rudd, 2009). Online venture capital markets can sponsor unaddressed brackets: enabling investments of magnitude currently underserved by traditional investors. Second, online markets seem particularly attractive for entrepreneurs, who try to reach a broad audience of investors, but initially lack the social circle to present their ideas. Third, the increased speed of access to capital may constitute an additional advantage of such marketplaces.

Online knowledge markets also allow knowledge owners to access non-financial complementary assets. Entrepreneurs who list their inventions can find knowledge seekers that are endowed with complementary assets needed for the commercialization of the invention. Similarly, established firms with existing technologies can benefit from partners with diverse complementary assets and product market experience. Participation in online knowledge markets may enable them to reach beyond social circle or industry membership. Namely, established firms can find applications for their inventions in novel or distant product markets, and profit from commercialization while facing a lower rent dissipating effect (Fosfuri, 2006).

From a process perspective, online knowledge market provide a structured approach towards translating, listing and potentially transacting on existing business plans or technologies. Consequently, an online knowledge market can be a valuable tool in a firm's strategy of commercializing external technologies as highlighted by Dave Christensen, Manager of Intellectual Property Process at GE Industrial Systems:

"What do Internet technology transfer tools do for an R\&D organization? For GE Industrial Systems, these tools provide global access, important for internal collaboration as well as externally maximizing exposure to potential licensees. These tools also help focus limited resources, giving shape and substance to what is usually a very fuzzy process." (Yet2.com, 2008b) 
It is important to note that the Internet is not a panacea. In particular, knowledge owners, whether they are individual entrepreneurs or innovative firms, need to be aware of substantial risks when participating in online knowledge markets. They have to make careful decisions as to what inventions to list in on online markets, and which ones to not make public to a large crowd of often anonymous knowledge seekers (Palomeras, 2007). Despite these shortcomings, the use of online knowledge markets is still in its infancy, and the next decades might tell whether an $e$ Bay for ideas is feasible, or a mere fantasy. 


\section{REFERENCES}

Acs, Z. \& Tarpley, F. 1998. The angel capital electronic network (ACE-Net) 1. Journal of Banking \& Finance, 22(6-8): 793-797.

Agrawal, A. 2001. University-to-industry knowledge transfer: literature review and unanswered questions. International Journal of Management Reviews, 3(4): 285-302.

Akerlof, G. A. 1970. The market for lemons: quality uncertainty and the market mechanism. Quarterly Journal of Economics, 89(3): 488-500.

Amit, R., Glosten, L., \& Muller, E. 1990. Entrepreneurial ability, venture investments, and risk sharing. Management Science, 36(10): 1232-1245.

Angel Investment Network; Entrepreneur FAQ; http://www.angelinvestmentnetwork.co.uk/entrepreneur/44, 2008.

Angelsoft; Who will see my deal?; http://blog.angelsoft.net/2008/07/15/who-will-see-my-deal/, 2008.

Anton, J. \& Yao, D. 1995. Start-ups, spin-offs, and internal projects. Journal of Law, Economics, and Organization, 11(2): 362-378.

Anton, J. \& Yao, D. 2005. Markets for partially contractible knowledge: bootstrapping versus bundling. Journal of the European Economic Association, 3(2-3): 745-754.

Ariño, A., de la Torre, J., \& Smith Ring, P. 2005. Relational quality and inter-personal trust in strategic alliances. European Management Review 2: 15-27.

Arora, A. 1995. Licensing tacit knowledge: intellectual property rights and the market for know-how. Economics of innovation and new technology, 4(1): 41-60.

Arora, A., Fosfuri, A., \& Gambardella, A. 2001. Markets for technology: The economics of innovation and corporate strategy: MIT Press.

Arora, A. \& Gambardella, A. 2009. Ideas for Rent: An Overview of Markets for Technology. Industrial and Corporate Change.

Arrow, K. 1962. Economic welfare and the allocation of resources for invention. 1962.

Arrow, K. 1974. The limits of organization: WW Norton \& Company.

Bakos, J. Y. 1997. Reducing buyer search costs: Implications for electronic marketplaces. Management Science, 43(12): 1676-1692.

Bakos, Y. 1998. The emerging role of electronic marketplaces on the Internet. Communications of the Acm, 41(8): 35-42.

Chesbrough, H. \& Smith , E. 2000. Patent \& License Exchange: Enabling a Global IP Marketplace. Harvard Business School Case No. 601019.

Chesbrough, H., Vanhaverbeke, W., \& West, J. 2006. Open innovation: Researching a new paradigm: Oxford University Press, USA.

Coase, R. 1960. The problem of social cost. The journal of Law and Economics, 3(1): 1.

Cohen, W., Nelson, R., \& Walsh, J. 2002. Links and impacts: the influence of public research on industrial R\&D. Management Science, 48(1): 1-23.

Cohen, W. M. \& Levinthal, D. A. 1990. Absorptive capacity: a new perspective on learning and innovation. Administrative Science Quarterly, 35(1): 128-152.

Cohen, W. M., Nelson, R. R., \& Walsh, J. 2000. Protecting their intellectual assets: appropriability conditions and why U.S. manufacturing firms patent (or not). NBER, wp 7552.

Coleman, J. 1990. Foundations of social theory: Harvard University Press. 
Colombo, M. \& Grilli, L. 2007. Funding gaps? Access to bank loans by high-tech start-ups. Small Business Economics, 29(1): 25-46.

Dushnitsky, G. 2010. Entrepreneurial Optimism in the Market for Technological Inventions. Organization Science 21(1): 150-167.

Dushnitsky, G. \& Lenox, M. 2005. When do firms undertake R\&D by investing in new ventures? Strategic Management Journal, 26(10).

Fishback, B., Gulbranson, C., Litan, R. M., \& L. Porzig, M. 2007. Finding Business "Idols": A New Model to Accelerate Start-Ups. Kauffman Foundation Report, 4.

Fosfuri, A. 2006. The licensing dilemma: understanding the determinants of the rate of technology licensing. Strategic Management Journal, 27(12): 1141.

Fosfuri, A. \& Giarratana, M. 2010. Introduction: Trading under the Buttonwood--a foreword to the markets for technology and ideas. Industrial and Corporate Change, 19(3): 767.

Fried, V. \& Hisrich, R. 1994. Toward a model of venture capital investment decision making. Financial management, 23(3): 28-37.

Gambardella, A., Harhoff, D., \& Verspagen, B. 2008. The value of European patents. European Management Review 5, 69-84

Gans, J. \& Stern, S. 2010. Is there a market for ideas? Industrial and Corporate Change.

Gans, J. S. \& Stern, S. 2003. The product market and the market for "ideas": commercialization strategies for technology entrepreneurs. Research Policy, 32(2): 333-350.

Giuri, P. \& Mariani, M. 2009. When distance does not matter: Inventors, education, and the locus of knowledge spillovers working paper.

Grant, R. M. 1996. Toward a knowledge-based theory of the firm. Strategic Management Journal, 17: 109-122.

Gulati, R. 1995. Does familiarity breed trust? The implications of repeated ties for contractual choice in alliances. The Academy of Management Journal, 38(1): 85-112.

Hagedoorn, J. \& Schakenraad, J. 1994. The effect of strategic technology alliances on company performance. Strategic Management Journal, 15(4): 291-309.

Hall, B.H., Thoma, G., \& Torrisi, S. 2009 Financial patenting in Europe. European Management Review 6, 45-63

Hallen, B. 2007. The Origin of the Network Positions of New Organizations: How Entrepreneurs Raise Funds. working paper.

Hargadon, A. \& Sutton, R. I. 1997. Technology brokering and innovation in a product development firm. Administrative Science Quarterly, 42: 716-749.

Ideacrossing; FAQ; https://www.ideacrossing.org/FAQs.aspx, 2008.

Jensen, R. \& Thursby, M. 2001. Proofs and prototypes for sale: The licensing of university inventions. American Economic Review, 91(1): 240-259.

Jeppesen, L. B. \& Lakhani, K. R. 2009. Marginality and problem solving effectiveness in broadcast research. Organization Science, Forthcoming.

Kaplan, S. \& Strömberg, P. 2004. Characteristics, contracts, and actions: Evidence from venture capitalist analyses. Journal of Finance: $2177-2210$.

Katz, M. \& Shapiro, C. 1994. Systems competition and network effects. The Journal of Economic Perspectives, 8(2): 93-115.

Kirsch, D., Goldfarb, B., \& Gera, A. 2009. Form or substance: the role of business plans in venture capital decision making. Strategic Management Journal, 30(5): 487-515. 
Lamoreaux, N. \& Sokoloff, K. 2003. Intermediaries in the US Market for Technology, 1870-1920. Finance, Intermediaries, and Economic Development: 209-246.

Laursen, K. \& Salter, A. 2004. Searching high and low: what types of firms use universities as a source of innovation? Research Policy, 33(8): 1201-1215.

Lazear, E. 1999. Output-based pay: Incentives, retention or sorting? working paper.

Leland, H. \& Pyle, D. 1977. Informational asymmetries, financial structure, and financial intermediation. Journal of finance, 32(2): 371-387.

Lemley, M. \& Myhrvold, N. 2008. How to Make a Patent Market.

Levin, R., Klevorick, A., Nelson, R., Winter, S., Gilbert, R., \& Griliches, Z. 1987. Appropriating the returns from industrial research and development. Brookings papers on economic activity, 1987(3): 783831.

Lichtenthaler, U. 2005. External commercialization of knowledge: review and research agenda. International Journal of Management Reviews, 7(4): 231-255.

Lowe, R. 2001. Entrepreneurship and information asymmetry: Theory and evidence from the university of california. University of California-Berkeley.

Nelson, R. \& Winter, S. 1982. An evolutionary theory of economic change: Belknap Press.

NVST; Customer Testimonials; http://www.nvst.com/press/pnvTestimonial.asp, 2008.

OECD. 2006. OECD Technology Indicators, Technology Balance of Payment-Payments/Receipts. $\underline{\mathrm{OECD}}$, Paris.

Palomeras, N. 2007. An analysis of pure-revenue technology licensing. Journal of Economics \& Management Strategy, 16(4): 971-994.

Parker, G. G. \& Van Alstyne, M. W. 2005. Two-Sided Network Effects: A Theory of Information Product Design. Management Science, 51(10): 1494-1504.

Pipkin R - East Coast Account Manager Angelsoft; Angelsoft Blog; http://angelsoft.net/blog/, 2008.

Powell, W., Koput, K., \& Smith-Doerr, L. 1996. Interorganizational collaboration and the locus of innovation: Networks of learning in biotechnology. Administrative Science Quarterly, 41(1): 116145.

RaiseCapital.com; FAQ; http://raisecapital.com/faq.php\#faq15, 2008.

Rivkin, J. W. 2001. Reproducing knowledge: replication without imitation at moderate complexity. Organization Science, 12(3): 274-293.

Robbins, C. 2009. Measuring payments for the supply and use of intellectual property. International Trade in Services and Intangibles in the Era of Globalization: 139.

Rosenberg, N. \& Birdzell, L. 1986. How the West grew rich: The economic transformation of the industrial world: Basic Books.

Rudd, R. 2009. Close the funding gap for smaller businesses, Financial Times, October 30: 15.

Sahlman, W. 1990. The structure and governance of venture-capital organizations. Journal of financial economics, 27(2): 473-521.

Scherer, F., Harhoff, D., \& Kukies, J. 2000. Uncertainty and the size distribution of rewards from innovation. Journal of Evolutionary Economics, 10(1): 175-200.

Seabrook, J. 1994. The flash of genius. The New Yorker, 11: 38-52.

Shane, S. \& Cable, D. 2002. Network ties, reputation, and the financing of new ventures. Management Science: $364-381$. 
Shane, S. \& Stuart, T. 2002. Organizational endowments and the performance of university start-ups. Management Science: $154-170$.

Silveira, R. \& Amit, R. 2006. Capital Flows and the Venture Financing Cycle. working paper.

Sorenson, O. \& Stuart, T. E. 2001. Syndication networks and the spatial distribution of venture capital investments. American journal of sociology, 106(6): 1546-1588.

Stigler, G. 1961. The economics of information. The Journal of Political Economy, 69(3).

Stuart, T. E., Hoang, H., \& Hybels, R. C. 1999. Interorganizational endorsements and the performance of entrepreneurial ventures. Administrative Science Quarterly, 44: 315-349.

Technology Transfer Tactics; The promise and pitfalls of using an IP exchange; http://www.technologytransfertactics.com/content/reprints/408-ip-exchange/, 2008.

Teece, D. J. 1977. Technology transfers by multinational firms: The resource cost of transferring technological know-how. Economic Journal, 87: 242-261.

Teece, D. J. 1986. Profiting from technological innovation: implications for integration, collaboration, licensing and public policy. Research Policy, 15(6): 285-305.

Verona, G., Prandelli, E., \& Sawhney, M. 2006. Innovation and virtual environments: Towards virtual knowledge brokers. Organization studies, 27(6): 765-788.

Winter, S. G. 1987. Knowledge and competence as strategic assets. In D. J. Teece (Ed.), The competitive challenge: strategies for industrial innovation and renewal: 159-184. Cambridge, MA: Ballinger.

Yet2.com; The Mission of the Marketplace; http://www.yet2.com/app/about/about/com, 2008.

Yet2.com; Industry Feature; http://www.yet2.com/app/insight/insight/20001203 christensen, 2008.

Zahra, S, Keil, T., \& Maula, M. 2005. New ventures' inward licensing: examining the effects of industry and strategy characteristics. European Management Review 2, 154-166

Zott, C. \& Huy, Q. 2007. How entrepreneurs use symbolic management to acquire resources. Administrative Science Quarterly, 52(1): 70-105. 
Table 1 Online Knowledge Marketplaces

\begin{tabular}{|l|l|l|}
\hline Firm & Website & Category \\
\hline Flintbox*** & www.flintbox.com & IPM \\
\hline iBridgenetwork*** & www.iBridgenetwork.com & IPM \\
\hline Ideaconnection (IPM)* & www.ideaconnection.com & IPM \\
\hline Knowledgeexpress (Free eMarket) & www.knowledgeexpress.com & IPM \\
\hline NewIdeaTrade & www.newideatrade.com & IPM \\
\hline Patentcafe (2XFR) & www.patentcafe.com & IPM \\
\hline Pharmalicensing & www.pharmalicensing.com & IPM \\
\hline Pharma-Transfer & www.pharma-transfer.com & IPM \\
\hline SparkIP & www.sparkip.com & IPM \\
\hline Taeus & www.taeus.com & IPM \\
\hline Techtransferonline & www.techtransferonline.com & IPM \\
\hline Tynax & www.tynax.com & IPM \\
\hline V-Capital (IPM)* & www.v-capital.com & IPM \\
\hline Yet2 & www.yet2.com & IPM \\
\hline ACE-Net (ActiveCapital)*** & www.activecapital.org & VCM \\
\hline Angel Investment Network** & www.midatlanticinvestmentnetwork.com & VCM \\
\hline Angelsoft & www.angelsoft.net & VCM \\
\hline Bizbuysell & www.bizbuysell.com & VCM \\
\hline Businessfinance & www.businessfinance.com & VCM \\
\hline Fundingspost & www.fundingpost.com & VCM \\
\hline Go Big Network & www.gobignetwork.com & VCM \\
\hline go4funding & www.go4funding.com & VCM \\
\hline Ideaconnection (VCM)* & www.ideaconnection.com & VCM \\
\hline Ideacrossing & www.ideacrossing.org & VCM \\
\hline Mergernetwork & www.mergernetwork.com & VCM \\
\hline NVST & www.nvst.com & VCM \\
\hline Raisecapital & www.raisecapital.com & VCM \\
\hline VCAOnline & www.vcaonline.com & VCM \\
\hline V-Capital (VCM)* & www.v-capital.com & VCM \\
\hline vFinance & www.vfinance.com & VCM \\
\hline & & \\
\hline
\end{tabular}

* sites which offer both VCM and IPM but have different levels of entry to list and search those markets.

** Angel Investment Network has subsidiaries all over the world. The Midatlantic Investment Group is one of the subsidiaries.

$* * *$ not for profit 
Table 2 Screening Mechanisms by Marketplace Category

\begin{tabular}{|l|l|l|l|l|}
\hline & $\begin{array}{l}\text { Disclosure- } \\
\text { Screen }\end{array}$ & $\begin{array}{l}\text { Contingent- } \\
\text { Payment- } \\
\text { Screen }\end{array}$ & No Screen & Total \\
\hline IPM & $2(14.2 \%)$ & $10(71.4 \%)$ & $2(14.2 \%)$ & $14(100 \%)$ \\
\hline VCM & $5(31.2 \%)$ & $10(62.5 \%)$ & $1(6.2 \%)$ & $16(100 \%)$ \\
\hline Total & $7(23.3 \%)$ & $20(66.7 \%)$ & $3(10 \%)$ & $30(100 \%)$ \\
\hline
\end{tabular}

Table 3 Contingent-Payments-Screen by Marketplace Category and Participant Type

\begin{tabular}{|l|l|l|}
\hline & NO CP-Screen & CP-Screen \\
\hline $\begin{array}{l}\text { Knowledge } \\
\begin{array}{l}\text { Owners (e.g. } \\
\text { entrepreneurs, } \\
\text { inventors) }\end{array}\end{array}$ & IPM: 4 (28.6\%) & IPM: 10 (71.4\%) \\
\hline $\begin{array}{l}\text { Knowledge } \\
\begin{array}{l}\text { Seekers (e.g., } \\
\text { investors, } \\
\text { licensees) }\end{array}\end{array}$ & IPM: $12(85.7 \%)$ & VCM: $10(62.5 \%)$ \\
& Total: 10 $13(81.2 \%)$ & Total 20 \\
\hline
\end{tabular}

